\title{
Response to my Commentators
}

\author{
Richard Swinburne
}

[Swinburne, Richard, 2002, "Response to my Commentators", Religious Studies, 38, 301-315]

\begin{abstract}
This paper contains my responses to the discussions of my views on the nature of God by Howard Robinson and Herman Philipse, my views on the strength of arguments for the existence of God by Herman Philipse, Brian Leftow, Timothy Mawson, and Christoph Jager, and my views on the nature and justification of Christian faith by Mark Wynn and Cyrille Mawson, contained in this issue of Religious Studies.
\end{abstract}

It is a very considerable honour for me that a whole issue of Religious Studies should consist of papers commenting on my work. I am mot grateful to the Editors, Robin Le Poidevin and Mark Wynn, for agreeing to this, to Timothy Mawson for guest-editing this issue, and to all the contributors for some very incisive papers. I am probably best known for the trilogy on theism which I wrote in the late seventies of the last century, and have substantially rewritten in this century - The Coherence of Theism (1977, 2016), The Existence of God (1979, 2004), and Faith and Reason (1981, 2005). So it is not surprising that the papers focus almost entirely on one or other of these books. My references to these books (hereafter CT, EOG, FR) are to their second editions.

\section{I}

The Coherence of Theism was concerned with the meaning and internal coherence of the claim that there is a God. In that book I pointed out that 'There is a God' could be understood in many different ways, according to the different ways in which the divine properties, such as 'omnipotence', 'omniscience', 'perfect freedom' etc. are understood. But I went on to develop an account of "There is a God' as 'There is a being who is essentially everlasting, omnipotent, lacks thisness, and is ontologically necessary', which, I claimed (CT,295) is 'close to Christian and other theistic accounts of God's nature. I claimed that variants of all the divine properties such as 'being a person' 'omniscience', 'perfect freedom', and 'moral goodness' are all entailed by 'omnipotence', understood in a wide sense; and I argued that it is simpler to suppose that a being omnipotent (in a wide sense) has these properties essentially, lacks thisness (that is, is what he is solely in virtue of these properties) and is ontologically necessary (that is, is, in a sense, the cause of his own existence). (This latter claim was new to the 2016 edition of CT.) I explained this same view (excluding the claim that God is 
ontologically necessary in my sense) in different terminology in The Christian God (henceforward CG, 1994), which Howard Robinson quotes, the view that God is 'pure limitless intentional power'. In saying that he is 'pure power', rather than 'has' power, I was making the point that there is no underlying 'thing' which is not a property in which the divine properties inhere. The power is 'intentional' because God acts to fulfil purposes. The power is 'limitless' both in time and so God is 'everlasting', and in quantity and so God is omnipotent, with all that follows from that.

This account of God has been subject to much criticism from 'classical theists', in effect mainly Thomists, as 'too anthropomorphic'. Their main point is that God must be thought of as absolutely 'simple', and that an account such as mine does not recognise that for God to be 'simple' the various properties of God must be the same as each other and the same as God himself; and that what it is to be God, that is his essence, must be the same as his existence. The trouble with this way of talking is that it doesn't seem to make any sense. How can the property of being powerful be the same property as the property of being wise, and how can a property be the same as the object to which it belongs? But there are senses in which some of these claims are true, and I spelled these out in $C G$. While being powerful is a different property from being wise, God (as defined by me) being all-powerful (omnipotent in my wide sense) mutually entails God being all-wise (omniscient, in the weak sense which I defined), and so generally for all the essential properties of God; God having any essential property is made true by his having any other essential property. And there is a sense in which God is the same as his having his essential properties, and so the same as his having any one of them, in that, since he does not have thisness, there is nothing more to the existence of God than the instantiation of his properties. But I cannot see that there is any sense in which God's essence is his existence unless these mutually entail each other - and that would only be true if it is logically necessary, or 'metaphysically necessary' in the Kripke-Putnam sense; and that, I have argued, is not logically possible (CT,262-271).

Howard Robinson has shown that there are also respects other than those just mentioned, in which the differences between my views and those of classical theism are due merely to our using different terminology. I much appreciate Robinson's attempt to bridge the gap between my views and those of classical theism. There is however apart from the difference about the sense in which God is a necessary being, one important further difference, and on this Robinson aligns himself with classical theism. Classical theism holds that God is timeless; all that he is or does occurs in one timeless moment which is neither before, or after, or simultaneous with any moment on our time scale. On this I stand by my argument 
that in order to make sense of the coincidence between God's beliefs about what humans do freely, and those free actions, those actions must cause God's beliefs; and that the causation of one event by another involves a temporal relation of the one to be other. Robinson acknowledges $(\mathrm{HR}, 9)$ that 'God's knowledge depends on the fact that there was the action in question', but claims that it does not follow that 'this is a causal "because"'; rather, 'it is by his action that he knows'. I can make no sense of this. As classical theists normally acknowledge, when doing a free action, humans are not caused to act by God; the initiative begins with humans. How then can any divine action make it the case that God has a true belief unless he is sensitive to what humans are doing - and 'sensitive to ' means 'open to effects caused by'?

The other contributor who commented on my account of the divine nature is Herman Phillipse (HP, 3-5) who asserts that merely to claim that God is 'without a body' entails that he is not a 'person' in a literal sense; and hence psychological predicates such as 'knowing' or 'is morally good' could not apply to him in any literal sense. This leads Phillippe to claim that theology uses so many words in analogical senses that it conveys virtually nothing by what it claims. I apologize to Phillipse and to other contributors that the second edition of $C T$ was published only in the summer of 2016, and so they could not be expected to have read much (if any) of it. But I did discuss in that edition $(\mathrm{CT}, 57-8)$ Phillipse's argument for his view that because the paradigm examples of human beings are bodily things, to speak of 'non-embodied persons' is to use 'person' analogically. I argued that it does not follow from the paradigm examples of x's all being $\phi$, that one cannot say literally that are x's which are not - $\phi$. The paradigm examples of 'persons' from which most contemporary English-speaking children learn its use are twenty-first century English speakers. But that does not entail that when they read in a book that there were on earth many humans and so persons thousands of years ago, or that there may be non-human persons on some distant planet, that the word 'person' is being used analogically. We learn the meanings of words by learning not merely what I called 'semantic rules' for their use - that is paradigm examples to which they apply, but also what I called 'syntactic rules' which are rules about which words entail the former words and which words are entailed by them; and thereby we learn which properties are essential for being an object of a certain kind and which are not. The mere fact that we believe that there are no $x^{\prime} s$ which are not- $\phi$ doesn't have the consequence that anyone who says that there are $x^{\prime}$ s which are not- $\phi$ is talking nonsense. To learn the syntactic rules we must study linguistic usage and reflect on possible scenarios to see what it would be like for there to be an $\mathrm{x}$ which is not- $\phi$. And I argued in detail (CT,104-125) that it makes perfectly 
good sense to talk of non-embodied persons. But of course I do not deny that some words used of God are used analogically; and to say that the God whom I sought to describe is a person does - as Herman acknowledges - involve using 'person' (though not most psychological predicates) in an analogical sense. But I also claimed (CT,59-75) that when we claim that some word is being used 'analogically', we need to specify in which respects the rules for its use are being changed, and to justify the claim that to say that an object has the property designated by word in its new sense conveys comprehensible information.

\section{II}

The Existence of God sought to provide a probabilistic cumulative argument from the existence and general features of the universe for the existence of the God analysed in CT. It claims that, since that God is a very simple being, simpler than any other being which would lead us to expect these phenomena, there is a greater intrinsic probability (that is, prior probability, given no logically contingent evidence) of his existence than that of any other such being. It then argues that, as we consider more and more evidence the existence of a universe, its conformity to order described by laws of nature, these laws and the boundary conditions of the universe being such as to cause the existence of human bodies, these being the bodies of conscious beings, and so on - the posterior probability of the existence of God becomes on all the evidence considered greater than a half. It argued also that the existence of suffering and wrongdoing does not lower that probability significantly. I brought out the structure of this argument with the aid of Bayes's theorem of the probability calculus.

Although Herman Phillipse argued that theism is not a 'meaningful theory' (HP5), he does however proceed to adduce many detailed objections to my cumulative argument for its truth, which would - he claims - apply if it were meaningful. Alas, for reasons of space, I can consider only the most important of these objections. It is crucial for my argument, as Phillipse recognizes, that we can know to some extent the kind of universe which God, if he exists, would create. We do know this, I claim, because it follows from the divine properties (those of the simplest and so most probable kind of God) that he is perfectly good, and we have sufficient knowledge of the fundamental moral principles to infer what a perfectly good being who has the other divine properties will do. I argue (for example, in CT 204-218) that the fundamental moral principles are necessary truths and to some extent knowable; moral principles which apply only to certain groups or in certain situations are logically supervenient on the fundamental principles, given certain contingent truths about the nature of those groups or situations. Phillipse's examples do not, as he seems to think count against this view. 
Phillipse holds that all knowable moral truths are truths about members of a 'group or tribe or biological species' (HP,8). We may well in practice begin our moral thinking by thinking about apparent truths of this kind. But we then ask ourselves if there is any more fundamental principle from which such truths would follow as a special case; reasons for supposing some suggested fundamental principle is true include the reason that it is simple and the reason that it would explain more than one lower-level apparent truth. (See again CT, 204-218.) Now consider two of his examples, 'one ought to honour one's mother and father' and 'one ought to care for one's children', which apply respectively only to children and parents. But there are fairly obvious fundamental principles satisfying at least one of my suggested reasons, from which these more limited principles follow - the principles 'one ought to honour one's benefactors' and 'one ought to care for those rational beings whom one has caused to exist'. It follows from the first principle that human children ought to honour their parents. But God gives human parents the power to have a child, and chooses which rational being that child will be (because a particular fertilized egg could become the body of any of an infinite number of possible rational beings). So, since God is so much greater a benefactor than are our human parents, all humans ought to honour him with far greater honour. It follows from the second principle that human parents ought to care for their children. Hence again since God is to much more the source of the existence of each of us than are our parents, he has a very great duty to care for us. Various further detailed consequences of the fundamental principles for humans and for God follow from contingent truths about humans and contingent truths about God. For example, it follows from the fact that we can exercise the powers we currently have only during the course of our earthly lives, that our human obligation to benefit our children is an obligation to be on balance their benefactor during our earthly life; but since God has an ability to benefit them over a longer period, he is obliged to be on balance a benefactor only over a longer period. Phillipse holds (HP,89) that agents only form 'morally motivated' intentions because they 'need' to do certain things; and so, because a God would have no needs, he would not form such intentions. But ordinary humans form many intentions to bring about states of affairs which they don't have any 'need' to bring about, but just because it is 'good ' that those states of affairs should exist. God's goodness would lead him to produce good states of affairs.

Phillipse writes $(\mathrm{HP}, 9)$ that I claim that theism resembles a scientific theory because it is empirically testable'. I very much doubt that I ever made any such claim. A scientific theory can only be probably true if it has observable consequences, but I argued (EG, 69-70) that it is irrelevant whether those consequences are known 
before or after the theory has been formulated. I cited the example of Newton's theory of gravitation, formulated in 1687 and recognised by so many scientists of that time as almost certainly true because it was a simple theory which entailed the operation of so many otherwise diverse lower-level laws (Kepler's law of planetary motion, Galileo's law of fall, the motions of tides, comets and planetary moons etc.), which laws were already well-known. But Newton's theory yielded no new predictions which could be tested for the next fifty years. We already have the observable evidence for theism - the existence of the physical universe, its conformity to simple laws etc. etc. Theism explains why that's how things are. I don't wish to deny that theism yields predictions about the nature of the afterlife and perhaps also other predictions which are not testable now; I am merely claiming that it doesn't need to make successful predictions of events observed after the formulation of the theory in order to be a theory 'resembling a scientific theory'.

Brian Leftow discusses the first stage of my cumulative argument, the 'cosmological argument' from there being a universe; and is in fundamental agreement with me that God is a simple being, and that it is more probable that there will be a universe if there is a God than if there is no God (or other supernatural being). I am grateful for his support, and find little in what he writes from which to dissent (apart from his claim about the plausibility of there being a metaphysically necessary being (in the now familiar sense). I need to make only three minor points, the first two of them to clarify misunderstandings of my terminology. First, it looks as if he misunderstands the role of my criterion of 'scope'. See for example BL,6. In my sense of 'scope' which may be different from that of Oppy whose views on scope he also quotes, the scope of a hypothesis is not what it succeeds in explaining, but what it makes probable - whether or not that is known to occur; so the scope is greater, the greater the content or extent of the claims to which it is committed. It is thus an a priori factor in the assessment of the probability of a hypothesis, and the greater the scope, the lower the intrinsic probability. So whatever observations are made, 'all ravens are black' has greater scope than (more content than) 'all ravens in England are black'. Although the greater the scope, the lower the intrinsic probability, I claim that simplicity outweighs scope, and so in general simpler theories with greater scope have greater intrinsic probability than less simple theories with smaller scope. Secondly, Leftow suggests $(B L, 1)$ that 'economy of ideology' is a criterion of prior probability additional to simplicity. As I spelled it out (EG,53) 'the simplicity of a theory ... is a matter of it postulating few (logically independent) entities, few properties of entities, few kinds of entities, few kinds of properties, properties more readily observable, few separate laws with few terms relating few separate 
variables, the simplest formulation of each laws being mathematically simple'. 'Economy of ideology' is a matter of 'few kinds of entities', and so already included in my account of simplicity. Thirdly, Leftow gives far too much to Oppy when he seems to allow $(B L, 9)$ that naturalistic theories 'are more parsimonious than their theist rivals'. The parsimony of a theory is a matter of the fewness of the entities etc. of the theory, not of what the theory - if true explains. The explanation of the many data about which observable chemical substances combine with which other chemical substances in what ratio by mass and (in the case of gases) by volume is explained by a theory that the very many kinds of substances are each made of atoms of a few different kinds. What makes the atomic theory simpler is the fewness of the kinds of atom and not the fewness of the kinds of observable chemical substance. That is one reason why theism is so simple - it postulates only one entity with+ very few essential properties from which all its other essential properties follow. And that is why naturalism is so un-simple, since the hypothesis by which it seeks to explain all data is some initial or boundary condition and some ultimate laws of nature, all of which involve very many entities and properties thereof. These latter are explained by theism, and so are not part of that theory.

Timothy Mawson phrases the question of whether the most general observable features of the world make it probable that there is a God, in terms of whether, among possible worlds which have those features, the actual world includes God. If I understand his paper correctly, he is not raising objections to my cumulative probabilistic argument for the existence of God, but rather commending a different strategy for getting atheists to agree with me. He suggests that we should ask the atheist 'If naturalistic atheism (NA) were false, which world would probably be the actual world?', and he claims that the atheist should answer - on grounds of simplicity - a theistic world. Now Mawson does not mention possible evidence against the existence of God, such as the existence of pain and suffering; and many an atheist who takes this into account might reply that if NA were false, the actual world would probably be a world in which there are both good and evil divinities of limited power. But on the supposition that the only relevant evidence is the general observable features of the world mentioned above which the God of theism might be expected to bring about, Mawson then defines 'Creative Supernaturalism' (CS) $(\mathrm{TM}, 6)$ as the disjunction of all possible theories postulating the existence of supernatural beings or forces who bring about those general observable features. Put in terms of this notion, Mawson claims that the atheist must answer that if NA were false, our actual world would be a CS-world, and since a theistic world is the simplest world among CS-worlds, theism would be the most probable world among CS-worlds. Mawson 
is correct in supposing that that would be a reasonable answer for the atheist to give - at least given my arguments for the simplicity of theism. 'So far, so good'; but 'so far' is hardly any distance at all. For the atheist might add that it is still immensely probable that NA is true - among other reasons because there are so many variants of NA. NA covers infinities of infinities of possible worlds, each of which includes the observable features of the actual world, differing from each other in being governed by different 'laws', in some of which 'laws' are just statements about what actually happens, and in others of which 'laws' are statements about powers or postulate entities separate from the substances which they govern. And of course many of these worlds are multiverses of different kinds. And, the atheist will add, even if he supposes that the actual universe is none of these, there are infinities of possible CS-worlds, and so while the probability of a theistic world (that is, of the actual world being a world containing God)may be higher than that of any other world, it is still extremely small. A 'natural theology' needs to establish that theism is quite probable, which is far far more than establishing that if NA were false, a theistic world is the most probable world.

The only way to establish more than what Mawson has shown that the atheist should admit is to articulate the criteria which we use in our normal inductive reasoning to measure the probability of a hypothesis as a function of its intrinsic probability and its explanatory power. In my writing I have argued that the intrinsic probability of a hypothesis is a function of its simplicity and (inversely) of its scope; and that much simpler theories are not merely more probable than less simple ones, but immensely more probable. I claimed that our justified confidence in the predictions of well established scientific theories and in the retrodictions of well established historical claims show this. I then examined the criteria for the simplicity of a hypothesis and argued that theism has a greater intrinsic probability than any other possible hypothesis which would make it quite probable that the observable world would have the character it does; and so I claimed $(E G, 342)$ that theism was overall more probable than on the evidence of natural theology considered in that book.

It is on these issues of what are the criteria of prior probability, how much more probable is a simpler theory than a less simple theory, and how probable do different theories make the observable phenomena, that the outcome of the controversy between theist and atheist depends. And - despite Mawson - doing all this does involve reaching 'premises concerning what the world would have been like, were theism to have been false'(TM,1) which one does by assessing the probabilities of alternative theories under both NA and CS. Of course, as I have always emphasized, this can only be done in very 
rough non-quantitative terms. But it needs to be done if probabilistic arguments of natural theology are to be shown knowably sound.

Reading Mawson's paper brought it home to me just how misleading talk about the 'closeness' of possible worlds can be. David Lewis who, more than anyone else, was responsible for the popularity of the concept of 'closeness' between possible worlds, thought of 'closeness' between worlds as in some sense their similarity to each other. He then argued that 'if it were that $\mathrm{x}$, then it would be that $\mathrm{y}$ ' is to be analysed as 'some ...world where both $\mathrm{x}$ and $\mathrm{y}$ are true is more similar to our actual world, overall, than is any world where $\mathrm{x}$ is true and $\mathrm{y}$ is false'. (Lewis, 1986, 41); but he went as to add that 'we must use what we know about the truth and falsity of counterfactuals' (Lewis, 1986, 43) to find the right sort of similarity relation. If we start by supposing that we know what 'overall similarity' amounts to, theists might well think that - with $\mathrm{x}$ as 'God does not exist' and y as 'there exists (what Mawson calls a) God-minus', a 'God-minus world' is as close as can be to a 'God -world'; and so think that 'if there were no God, there would be a God-minus'. But that is surely false, because a 'God-minus' is so much less simple than a God, that the intrinsic probability of 'there is a God-minus' is very low, and so the posterior probability (on the evidence of the general features of the actual world) that the actual world is a God-minus world is very much lower than the posterior probability that the actual world is an NA-world. Anyway it seems to me that a 'God-minus world', is not a coherent world. A being who didn't know the trillioneth number in the decimal expansion of pi would fail to know an infinite number of other truths - for example all truths of the form ' $\{$ that trillionth number $+\mathrm{n}\}$ is divisible by $\mathrm{m}$ '. And a God-minus would not be essentially omnipotent, because he would not be able to give a true answer to the question 'what is that trillionth number?'. No doubt there is some coherent world which could be crafted, not too dissimilar from the 'God-minus' world, but it would have such an obviously ad hoc character, as to be intrinsically highly improbable.

Their context reveals how propositions of the form 'if $\mathrm{x}$ were true, y would be true' are to be analysed; that is, their context determines what background knowledge is assumed when we assume further that $\mathrm{x}$ is true and then we proceed to assess first the probability of y and then the probability of not-y. The probability of 'if $\mathrm{x}$, then $\mathrm{y}^{\prime}$ is the sum of the probabilities of $\mathrm{y}$ on each of the alternatives allowed within the range of $\mathrm{x}$ given the background knowledge; and similarily for the probability that if $\mathrm{x}$ were true, $\mathrm{y}$ would be false'. In the case of assessing the probability of how things would be if theism were false, Mawson supposes that the background knowledge assumed is the general overall features of the natural world. In that case - because God-minus kinds of world 
have such low intrinsic probability - to my mind the most probable world would be an NA-world, and the most probable CS-world be a world with a few feeble poltergeists. But neither of these worlds are in any normal sense of 'overall similarity', the world overall most similar to that of theism. Lewis $(1986,42)$ warns against interpreting 'overall similarity' in a naively literal way, but to my mind his talk of the 'closeness' of possible worlds encourages us to misassess the truth-values of counterfactuals.

Christoph Jäger has two criticisms of the articulation of my cumulative argument for the existence of God in terms of the probability calculus. The first criticism is $(\mathrm{CJ}, 9)$ that I give 'little or no independent argument' for the values which I ascribe to the crucial terms $\mathrm{P}(\mathrm{h} \mid \mathrm{k}), \mathrm{P}(\mathrm{e} \mid \mathrm{h} \& \mathrm{k}), \mathrm{P}(\mathrm{e} \& \sim \mathrm{h} \mid \mathrm{k})$ (with $\mathrm{k}$ as tautological background knowledge), in my final assessment of the probability of theism (h) on all the evidence (e) which I consider in EG apart from the evidence of religious experience I claim however that I do give independent arguments for the value of $\mathrm{P}(\mathrm{e} \mid \mathrm{h} \& \mathrm{k})$, the probability that a God would create a universe like ours, in Chapter 5. The perfect goodness of God makes it the case that there is a probability of 1 that God will do the best possible action where there is one, and a probability of $1 / 2$ that he will do a particular one of two equal best possible actions. I argued that it would be an equal best action for God to create (as opposed to not create) 'humanly free agents' because of the unique kind of goodness (the ability to choose between good and evil) which they have despite the evil which they might well cause. If we include in e only a substantial amount of evil, which may be less than the actual evil in the world, then $\mathrm{e}$ is necessary for the existence of such agents and so $\mathrm{P}(\mathrm{e} \mid \mathrm{h} \& \mathrm{k})=1 / 2$. But I then argued (EG, 263-7) that in order to take into account that there may be a somewhat larger quantity of actual evil in the world, for which theism could account only if we add to it the additional hypothesis that God provides a compensatory period of good life after death for some people, we should ascribe to $\mathrm{P}(\mathrm{e} \mid \mathrm{h} \& \mathrm{k})$ a somewhat lower value. I argued that that value needed to be only 'somewhat' lower, and I suggested for it (EG, 339)the value of 1/3.

My arguments for the values of the other terms can be seen if we take the formulation of Bayes's theorem which, as Jäger points out, I used in the second edition of EG:

$$
\begin{aligned}
& \mathrm{P}(\mathrm{h} \mid \mathrm{e} \& \mathrm{k})=\underline{\mathrm{P}(\mathrm{h} \mid \mathrm{k}) \mathrm{P}(\mathrm{e} \mid \mathrm{h} \& \mathrm{k})} \\
& \mathrm{P}(\mathrm{h} \mid \mathrm{k}) \mathrm{P}(\mathrm{e} \mid \mathrm{h} \& \mathrm{k})+\mathrm{P}(\mathrm{e} \mid \sim \mathrm{h} \& \mathrm{k}) \mathrm{P}(\sim \mathrm{h} \mid \mathrm{k})
\end{aligned}
$$

$\mathrm{P}(\sim \mathrm{h} \mid \mathrm{k})=1-\mathrm{P}(\mathrm{h} \mid \mathrm{k}) . \sim \mathrm{h}$ is equivalent to the disjunction of every universe (including the null universe) in which there is no God. If we suppose that it is a priori vastly improbable that there should exist 
anything at all logically contingent, we must suppose that $\mathrm{P}(\mathrm{h} \mid \mathrm{k})$ is very low, but (see EG, 109) it will not be nearly as low as the value of $\mathrm{P}\left(\mathrm{h}_{\mathrm{n}} \mid \mathrm{k}\right)$ for many rival hypotheses $h_{n}$ about what there is in view of the great simplicity of $h$. But almost all of these rivals $h_{n}$ are such that $\mathrm{P}\left(\mathrm{e} \mid \mathrm{h}_{\mathrm{n}} \& \mathrm{k}\right)=0$, since they are incompatible with the occurrence of e. I set out in chapter 14 the three rivals to $h$, which do give a significant value to $\mathrm{P}\left(\mathrm{e} \mid \mathrm{h}_{\mathrm{n}} \& \mathrm{k}\right)$ which Jäger lists $(\mathrm{CJ}, 7)$. I argued we should disregard $h_{3}$ (that the way the universe is is just a brute fact) since its intrinsic probability is 'infinitesimally low' (EG, 341). $\mathrm{h}_{1}$ and $\mathrm{h}_{2}$ are each a disjunction of an infinite number of alternatives. If we build enough into each of these alternatives (e.g. in $h_{2}$ ascribe to different minor deities the desires and powers which will quite probably bring about e) so that the probability of e given each is the same as $\mathrm{P}(\mathrm{e} \mid \mathrm{h} \& \mathrm{k})=0.3$, then everything turns on the values of $\mathrm{P}\left(\mathrm{h}_{1} \mid\right.$ $\mathrm{k})$ and $\mathrm{P}\left(\mathrm{h}_{2} \mid \mathrm{k}\right)$ relative to the value of $\mathrm{P}(\mathrm{h} \mid \mathrm{k})$. 'I argued in chapters 3 and 7 that our normal criteria of probability give a very simple hypothesis greater intrinsic probability than a disjunction of many alternative more complex hypotheses' (EG,340), and I should have written in the light of those earlier arguments, 'an infinite number' instead of 'many'. How much greater? Our criteria are too vague to give a sharp answer, and so I suggested as a reasonable compromise between possible values, when we take into account the nature of each of these hypotheses, that each of $\mathrm{P}\left(\mathrm{h}_{1} \mid \mathrm{k}\right)$ and $\mathrm{P}\left(\mathrm{h}_{2} \mid \mathrm{k}\right)$ are equal to half of $\mathrm{P}(\mathrm{h} \mid \mathrm{k})$. If we give to $\mathrm{P}(\mathrm{h} \mid \mathrm{k})$ the arbitrary value of 0.01 , each of the two main rivals then has the value 0.005. $\mathrm{P}(\mathrm{e} \mid \sim \mathrm{h} \& \mathrm{k}) \mathrm{P}(\sim \mathrm{h} \mid \mathrm{k})$ equals the sum of $\mathrm{P}\left(\mathrm{e} \mid \mathrm{h}_{\mathrm{n}} \& \mathrm{k}\right) \mathrm{P}\left(\mathrm{h}_{\mathrm{n}} \mid \mathrm{k}\right)$ for all the hypotheses which are rivals to $h$. For all these hypotheses except $h_{1}$ and $h_{2} P\left(e \mid h_{n} \& k\right)=0$. So $\mathrm{P}(\mathrm{e} \mid \sim \mathrm{h} \& \mathrm{k}) \mathrm{P}(\sim \mathrm{h} \mid \mathrm{k})=\mathrm{P}\left(\mathrm{e} \mid \mathrm{h}_{1} \& \mathrm{k}\right) \mathrm{P}\left(\mathrm{h}_{1} \mid \mathrm{k}\right)+\mathrm{P}\left(\mathrm{e} \mid \mathrm{h}_{2} \& \mathrm{k}\right) \mathrm{P}\left(\mathrm{h}_{2}|| \mathrm{k}\right)$ which has the same value as $\mathrm{P}(\mathrm{e} \mid \mathrm{h} \& \mathrm{k}) \mathrm{P}(\mathrm{h} \mid \mathrm{k})$, and so $\mathrm{P}(\mathrm{h} \mid \mathrm{e} \& \mathrm{k})=1 / 2$, as suggested in Jäger's table 2. If we suppose that it is a priori more (or less) probable than I supposed that there should exist anything at all logically contingent, we will ascribe to $\mathrm{P}(\mathrm{h} \mid \mathrm{k})$ a higher (or lower) value; but since the same considerations will lead us to ascribe correspondingly higher (or lower) values to $\mathrm{P}\left(\mathrm{h}_{1} \mid \mathrm{k}\right)$ and $\mathrm{P}\left(\mathrm{h}_{2}|| \mathrm{k}\right)$, the resultant value of $\mathrm{P}(\mathrm{h} \mid \mathrm{e} \& \mathrm{k})$ will remain $1 / 2$. This is the probability of $\mathrm{h}$ when all the evidence considered in $\mathrm{EG}$, apart from the evidence of religious experience, is taken into account; this is value which we should have reached in the last line of Jäger's tables 3 an 4 . Less evidence for $\mathrm{h}$ gives it a smaller probability.

I turn to Jäger's second criticism, that the Principle of Credulity (alias 'Dogmatism') is inconsistent with Bayesianism. The Principle claims 'that (in the absence of special considerations) if it seems (epistemically) to a subject that $\mathrm{x}$ is present (and has some characteristic), then probably $\mathrm{x}$ is present (and that characteristic),.' (EG,303.) So the evidence e possessed by a subject $S$ that it seems that Q is present' makes it probable on S's evidence that Q is 
present. Jäger follows recent discussions in pointing out that if e increases the probability of $h$ (because $h$ makes e probable), it will also increase the probability of those hypotheses incompatible with $h$ which also make e probable. These hypotheses are the 'sceptical alternatives' to $\mathrm{h}$ - for example, if 'I seem to see a hand' (e), this increases the probability that there is a hand there, but it also increases the probability that there is a fake hand there. But there will be many alternatives to $h$, incompatible with both $h$ and its sceptical alternatives whose probability is lowered by e; and that is why there is no inconsistency between 'dogmatism' and Bayesianism. Now Jäger considers an alternative to $h, h *$ which is my $\mathrm{h}_{2}$ - an initial state and laws of the physical universe which make probable the general features of the universe discussed in EG apart from religious experience. Jäger supposes that $h *$ makes e probable and so is a 'sceptical alternative' to $h$. But it is difficult to see how that particular $\mathrm{h}^{*}$ would make it probable that religious experience would occur, and only then would it be a 'sceptical' alternative. But given Jäger's supposition that $h *$ is a sceptical alternative to $h$, his formal conclusion follows. e makes $h$ probable (that is, more probable than not) only if e does not make $h^{*}$ probable. Since e raises the probability of $h^{*}$, e can only fail to make $h^{*}$ probable if the prior probability of $h^{*}$ is less than $1 / 2$. So Jäger is right to conclude that - given that one is only justified in believing a proposition if that proposition is probable, 'in order to be epistemically justified in believing $\mathrm{h}$ after considering religious experience, you must already be justified in believing that the naturalistic alternative to theism, $\mathrm{h}^{*}$, is false' $(\mathrm{CJ}, 15)$. If someone believes a particular atheistic theory which predicts that people will often have religious experiences, then having a religious experience is rightly not going to persuade him that there is a God. But the normal situation for an investigator is surely that while there are sceptical hypotheses alternative to $h$, there are very many other further hypotheses incompatible with both $\mathrm{h}$ and its sceptical alternatives, which do not predict e, and that no sceptical alternatives to $h$ have prior probabilities greater than $1 / 2$. In that normal situation Jäger's result does not cast doubt on the Principle of Credulity which states that in the absence of special considerations, an experience apparently of $\mathrm{P}$ makes it probable that $\mathrm{P}$ is there. The situation of a sceptical alternative with a prior probability greater than $1 / 2$ is simply a very unusual kind of 'special consideration'. And it would be very odd to suppose that any sceptical alternative to theism which predicted religious experience, had that level of probability. Contrary to Jäger $(\mathrm{CJ}, 16)$ it does not follow that if the probability of $\mathrm{h}$ before considering religious experience is 0.3 .., the probabilities of all the competing hypotheses which could explain the occurrence of religious experiences sum to 0.7.' All that follows is that the probabilities of all the hypotheses other than $\mathrm{h}$ which could explain the occurrence of the general 
features of the universe apart from religious experiences sum to 0.7. Many of those hypotheses will not explain religious experience (or, to be more precise, will not make its occurrence at all probable.)

\section{III}

The final two papers concern my treatment of faith. I claimed that to have the kind of 'faith' in the Christian God which is a virtue is to act on the assumption that there is a God who has the nature and has done the actions described in the Creed, in order to obtain the goals of the Christian religion; and that it is rational $_{5}$ (that is, rational in the strongest sense) to have such faith iff after adequate investigation it is more probable on your evidence that you will obtain the best religious goals by acting on that assumption rather than by acting on any incompatible assumption. So the rationality is a function of two probabilities, the probability of the Creed being true, and the probable goodness of the goals being sought. The Existence of God was concerned only with the former; Faith and Reason was concerned with the goodness of the goals of the Christian religion and with how these two probabilities fit together.

I argued that the three good goals of the Christian religion are to worship and obey God, to attain salvation for oneself, and to help others to attain their salvation. If one believes that the Christian creed is true, one will believe both that these goals are good goals and that they are attainable by following the Christian way - for it follows from the Creed that they are. But one may believe that such goals are good goals and so worth pursuing, even if it is somewhat more probable than not the Christian Creed is false; and so it is rational to pursue them, even where the only way to do so is by acting on the assumption that the Creed is probably true. Obvious secular examples illustrate this general point that it is rational to pursue goals which can only be attained if some assumption which you believe to be probably false, is true. Suppose you find yourself in an enemy country in time of war, when your only way of escaping from that country - a good goal, is by asking a citizen of that country to help. Of every such citizen you believe that he will not help but will instead hand you over to the police. But all the same it is rational to ask for help from that citizen of whom you believe it is more probable that he will help you than that any other citizen will help you. For otherwise you will not escape. Such examples also bring out that there are limits to how improbable your assumption can be, for it to be rational to act on that assumption. If it is immensely improbable that any citizen will help you, then perhaps it is better to stay in hiding and hope that - very improbably - some other way of escape will turn up. So also with the example of relying on the assumption that the Creed is true. If this is very improbable, it would be - almost certainly - a waste of time to pursue the Christian way in order to attain its goals. But if it is not too improbable, then it 
would be a rational thing to rely on the Creed if you have reason to believe that its goals are good goals, independent of the reason that it follows from the Creed.

I argued in Faith and Reason that there are independent good reasons to suppose that these goals are indeed good goals. With respect to the first goal, it would be so good to worship God if he exists, that it is good to do so even if probably he does not exist. I Illustrated how this might be a rational thing to do by an analogy (FR,223). Suppose that 'you receive a very expensive and much desired present and it is unclear who has sent it. Although you don't know who the donor is, you think that there is a significant probability (though less than one half) that it is S, and only a much smaller probability that it is anyone else known to you. It would then obviously be good and so rational to thank S properly, and bad not to make an effort to do so - even though you think it improbable that $S$ is the donor.' Mark Wynn suggests $(\mathrm{MW}, 12)$ that this account of the goodness of worship 'gives a rather negative cast to the religious life: we are to be motivated by the goal of not breaching a merely possible obligation'. But that there is more to it than that. It is always good to fulfil one's obligations; and a really good person will enjoy doing what is good. It is very good to receive a greatly worthwhile thing as a present from a benefactor (rather than that that good thing should have arrived by chance) and to express gratitude for it and thereby develop one's friendship with the benefactor; and so it is very good to do what one can towards locating the possible benefactor and developing that friendship, even if it is probable that one will not succeed.

I understood by 'salvation' in the second and third 'religious reasons to pursue a religious way' simply 'deep well-being', and I illustrated how the existence of God gives a depth to all good earthly activities which they would not otherwise have. But of course the Creed claims that there is a life after death in which all these good activities can be pursued in a much fuller way by those who pursue the Christian way in this life. And that provides a very substantial further reason for pursuing the Christian way now, that we may go on pursuing it in a fuller way, free from the obstacles in the way of pursuing it on earth, in circumstances where it is manifest that doing so has the deep significance which the existence of God gives it.

In general Wynn is fully supportive of the project of an 'apology' which argues for the worthwhileness of these good goals, and I find in his contribution little with which to disagree. I am very happy with his suggestion that my view should be 'located within a larger story of the goods of the religious life' as aiming at 'congruence with an already established theological context', so long as we bear in mind that that life may be pursued by someone who has considerable doubts about whether that context is 'established'. Wynn illustrates 
his claims (MS,9) about how the existence and actions of God give a depth to ordinary human pursuits when they are 'appropriately directed to God' which they would not otherwise have, by Aquinas's doctrine of the 'infused moral virtues'. For example the secular virtue of 'loving one's neighbour' has a greater depth and a wider scope when we regard it as extending to our enemies, since it is possible that we will share with them the Beatific Vision of God. I must add here that the existence of God makes a great difference to the status of all other humans, including our enemies, apart from whether or not they will attain the Beatific Vision, simply because, being created by God, they are in a very important sense our 'brothers' and 'sisters'. And the theological virtues, such as 'faith, hope, and the love of God' (MS,4) as Aquinas understands them, only have any point if there exists a God. In pointing out these goods Aquinas of course assumes the existence of God, and - in arguing for the goodness of religious goods - I do not; but I am arguing that they are so valuable to pursue that we need not assume that - although we need to believe that there is a modest probability of the truth of the Creed.

It is a consequence of my account of Christian faith that one may have and rationally have faith while believing that it is more probable than not that there is no God. Understandably some people, including Cyrille Michon have found this last claim 'paradoxical' (CM, 3), but I argued in its favour first from the nature of God who wants us by our own free choices to become saints, and secondly from the claim being implicit in some of the New Testament and later Christian tradition. On the former reason - humans can become saints by freely seeking the best, despite doubt about its attainability. One way in which God can make this possible for humans is by letting them become aware of the great religious goals which they might attain by pursuing the Christian way combined with sincere doubt about whether the Christian Creed is true and so whether pursuing that way will ever attain those goals. The virtue of pursuing the Christian way can be practiced both by those who believe on balance that the good is attainable and by those who believe on balance that it is not. Both are on the same road, and their virtue is of the same kind. Indeed those whose doubt is greater exemplify it more strongly. A good God must value greatly the friendship of those who so want his friendship that they work hard to obtain it even though they expect to fail. I illustrated the second reason by pointing to a few New Testament passages which implied that 'faith' sometimes involves significant doubt, and to Cyril of Jerusalem's defence of the view that it often involves very considerable doubt.

Michon however thinks that I have missed something very important: that faith involves trust in a person, and that trust is a 
good emotional attitude to have towards a person which should not depend on inductive arguments; and that having faith in God is trusting that what he tells us is true. However faith is supposed except perhaps in some Protestant traditions - to be 'voluntary'. So what is good about faith is not 'having trust' in God, but 'putting one's trust' in God. And with regard to putting one's trust in ordinary humans, I certainly believe that it is rational and so good to trust any human informant in the absence of reasons for doubting them. Such contrary reasons will be either reasons for doubting their honesty or competence as informants about the subject being discussed, or independent reasons for believing that what they say about it is false. And I believe that it is also good sometimes to put one's trust in someone who on balance one does not believe to be reliable, as in my example of trusting the enemy citizen and also in Michon's example $(\mathrm{CM}, 11)$ of putting one's trust in someone in order to maintain a relationship with them.

However there is an acute disanology between trusting an ordinary human and trusting God that they are telling us what is true, in that we normally know what the human has said - the only issue is whether what he has said is true; whereas we are not certain what God has said. If we knew what God had said, it would obviously be stupid not to trust him (since God is necessarily omniscient, and perfectly good). It is the Church who tells us what in its view God has told us. And again, it is rational and so good to trust the Church in the absence of reasons for doubting it. It may be that in some isolated medieval village no one has any reason to doubt what the Church through the mouth of the village priest tells them that God has told the Church. But in twenty first century Western society most people have reasons for doubting the Church, including the contrary testimonies of others which it is also rational to believe in the absence of contrary reasons. Atheist schoolteachers and academics tell us that science or philosophy has shown that there is no God; Muslim evangelists tell us that God revealed truths to us in the Koran, which contradict what the Church claims. And some people may have independent reasons of their own for doubting the honesty or competence of the Church, reasons constituted by some dishonest actions of priests and what they have learnt about how church doctrines came to be formulated; or they may have independent reasons for believing that there is no God. In this situation one does need a reason for trusting the Church. Many people may have evidence enough from their own religious experiences or from the testimony of their priest, their parents or their friends whom they judge to be more reliable than atheist schoolteachers and academics. Others may have the evidence provided by inductive arguments from the nature of the world and its history. These may be inductive arguments to show that God has guaranteed that the Church is a 
reliable source of information about what God has revealed, or arguments to show on independent grounds that a certain purportedly revealed truth is true.

Rival claims need to be compared for their reliability on the basis of evidence understood in a very wide sense, including one's 'feelings' - that is, one's basic beliefs - about the reliability of different informants. There is no merit in taking a 'leap' in one direction rather than another without assessing that evidence. I cannot see why any human should be 'offended' $(\mathrm{CM}, 6)$ by someone seeking evidence about their 'sincerity and competence' in a situation where others have questioned that honesty or competence, before trusting them in respect of what they have said. Nor should the Church or God himself be offended if in such a situation an inquirer looks for evidence that the Church is a reliable source about what God has revealed. God who gave us rationality would expect it. And in this it seems to me that I have the support of Aquinas. He held that the object of an act of will is something proposed to it by reason' (Summa Theologiae.Ia.2ae.19.5). So one has to have some reason for 'believing in Christ'. Hence, he concludes, if one's reason presents an act as a bad thing to do it would be wrong to do it; and that, he explicitly states includes the act of 'believing in Christ'. So I reject Michon's claim that my account of faith is too 'demanding on the rationality side' $(\mathrm{CM}, 12)$; as I have also rejected his claim that it is insufficiently demanding on the 'dogmatic side', when I advocated the view that faith need not involve more by way of belief than merely believing that it is more probable that pursuing the Christian way will attain the good goals of religion than that any other religious way will do so.

\section{BIBLIOGRAPHY}

1. 'HR', 'HP', 'BL', 'TM', 'CJ', 'MW', and 'CM' followed by a number refer to the page numbers of the typed versions respectively of the papers of Howard Robinson, Herman Phillipse, Brian Leftow, Tim Mawson, Christoph Jaeger, Mark Wynn, and Cyrille Michon.

2. CT, EG, FR, followed by a number refer to the page numbers of the second editions of my books The Coherence of Theism (Oxford University Press, 2016), The Existence of God (Oxford University Press, 2004), and Faith and Reason (Oxford University Press, 2005).

3. Lewis, David, 1986, Philosophical Papers vol II, Oxford University Press. 